\title{
Hydrologic Modeling Using SWAT and GIS, Application to Subwatershed Bab-Merzouka (Sebou, Morocco)
}

\author{
Yassine Bouslihim ${ }^{1}$, Ilias Kacimi' ${ }^{2}$, Hassane Brirhet ${ }^{3}$, Mourad Khatati ${ }^{4}$, Aicha Rochdi ${ }^{1}$, \\ Namira El Amrani Pazza1, Abdelhalim Miftah', Zainab Yaslo' \\ ${ }^{1}$ Research Team in Environmental Geosciences, Faculty of Science and Technology, Hassan 1 University, \\ Settat, Morocco \\ ${ }^{2}$ Faculty of Sciences, Mohamed V University, Rabat, Morocco \\ ${ }^{3}$ Faculty of Science and Technology, Sidi Mohamed Ben Abdellah University, Fes, Morocco \\ ${ }^{4}$ Research Team ERGO, Faculty of Science, Abdelmalek Essaadi University, Tetouan, Morocco \\ Email: vassine.bouslihim@gmail.com
}

Received 5 January 2016; accepted 16 February 2016; published 19 February 2016

Copyright (C) 2016 by authors and Scientific Research Publishing Inc.

This work is licensed under the Creative Commons Attribution International License (CC BY). http://creativecommons.org/licenses/by/4.0/

(c) (i) Open Access

\begin{abstract}
Water management in morocco faces significant challenges in both levels, quality and quantity, in order to address these challenges and to secure the rational and efficient management of water resources, it is necessary to try to understand the different issues involved in the water cycle works! The large number of hydrological studies and techniques used at the Sebou watershed are limited to water quality, and the use of the simpler empirical models, that, do not permit to take into consideration all the factors affecting flow and cycle of water. In the purpose of using the hydrological model SWAT to study the hydrological functioning of the Sebou watershed (Morocco) which faces many problems regarding the management of its water resources like all the other watersheds in our country, this study focuses on the creation, organization and generation of input data (soil, soil occupation, climate...) using a GIS (ARCGIS) then, the configuration and calibration of the model and after that, the evaluation of the results. The main reason behind this work is to measure the adaptability of this model to the selected area in order to generalize the model to the whole Sebou watershed. The results are satisfying; they show that this model can represent the overall hydrological regime of the pilot basin Bab-Merzouka. This model can open up new perspectives regarding the effects of climate change, and the changes caused by humans on water resources, in terms of both quantity and quality.
\end{abstract}

\section{Keywords}

Hydrological Functioning, SWAT, GIS, Sebou (Morocco)

How to cite this paper: Bouslihim, Y., Kacimi, I., Brirhet, H., Khatati, M., Rochdi, A., Pazza, N.E.A., Miftah, A. and Yaslo, Z. (2016) Hydrologic Modeling Using SWAT and GIS, Application to Subwatershed Bab-Merzouka (Sebou, Morocco). Journal of Geographic Information System, 8, 20-27. http://dx.doi.org/10.4236/igis.2016.81002 


\section{Introduction}

Watershed Sebou is the largest surplus in terms of water resources; it represents $28 \%$ of national potential surface water and $20 \%$ of ground water potential, with a high population density (19\% of the national population) [1].

Therefore, to study the hydrological behavior and to fight against pollution of the water resources in the basin, it is important to understand and quantify these resources, but above all, to help managers and decision makers to adopt the appropriate land management techniques. The use of a model to simulate the waterways will be a major decision-making tool [2].

There are, in the literature, many hydrological watershed models each with their specifics and scope, several studies have been developed in the Sebou catchment over the years, but all focus on simple empirical models that do not take into consideration a range of factors influencing the flow and the water cycle [3].

This component can be analyzed and approached only by using hydrological models with spatial component [4].

This work takes on the hydrological modeling of the same watershed using the SWAT (Soil and Water Assessment Tool) model developed by the United State's Department of Agriculture (USDA), which is a conceptual model, deterministic and semi-spatial, that takes into consideration several parameters (soil types, land use, topography...).

The semi-distributed physically based hydrological modeling is used to analyze the impacts of rainfall variability on stocks and flows of water in the different compartments of the water cycle at the catchment scale. It also takes into account the weight and spatial variability of other factors such as vegetation or soil.

The hydrological model SWAT is already tested on three areas in Morocco (Bouregreg [3], Oum ErRbiaa [5], Rhéraya [6]), in this work, we try to apply the model on the Sebou watershed.

The application of a model like SWAT requires very large spatio-temporal data of different types and sources, making the use of these models difficult [3], and especially in areas where the surface exceeds hundreds of square kilometers, the case of the pilot basin Bab-Merzouka, which has an area of around $1370 \mathrm{~km}^{2}$.

The main objective of this study is to test the capacity and performance of the physically based distributed hydrological model, to represent the hydrological behavior and the understand ding of the flow son the BabMezrouka Basin to generalize across the watershed Sebou.

The first part is devoted to the presentation of our methodology of work, and to describe the study area, the model used and the data used in the preparation of our database. The second part discusses the scope of the results obtained in the calibration/validation phase and confirms the possibility of working with the model (SWAT) to resolve the water resources management's problems in the watershed Sebou.

\section{Materials and Methodology}

\subsection{Presentation of the Study Area}

The study area covers the Bab-Merzouka sub-basin upstream of the watershed of the Sebou, with an area of $1370 \mathrm{~km}^{2}$, altitudes range between $359 \mathrm{~m}$ and $1777 \mathrm{~m}$. The climate in the Middle Sebou is the Mediterranean type with average temperatures between $11^{\circ} \mathrm{C}$ in winter and $28^{\circ} \mathrm{C}$ in summer. Annual rainfall is $560 \mathrm{~mm}$, significantly, above the national average $(300 \mathrm{~mm})$. The area knows the prevailing winds from the North East and North West.

\subsection{SWAT Presentation}

SWAT operates on a daily time step and is designed to predict the impact of land use and management on water, sediment, and agricultural chemical yields in ungauged watersheds. The model is process based, computationally efficient, and capable of continuous simulation over long periods. Major model components include weather, hydrology, soil temperature and properties, plant growth, nutrients, pesticides, bacteria and pathogens, and land management. In SWAT, a watershed is divided into multiple subwatersheds, which are then further subdivided into hydrologic response units (HRUs) that consist of homogeneous land use, management, topographical, and soil characteristics. The HRUs are represented as a percentage of the subwatershed area and may not be contiguous or spatially identified within a SWAT simulation. Alternatively, a watershed can be subdivided into only subwatersheds that are characterized by dominant land use, soil type, and management [7]. 


\subsection{Data Collection and Preparation}

The use of a highly parameterized model as SWAT requires initial preparation of a very large, multidisciplinary database. These data are essential to make use of this model, so the use of this model in developing countries or countries that do not have well-structured databases is a little difficult.

- The relief

The representation of the terrain of the Sebou catchment and the extraction of different morphological parameters (surface, basin boundary, river network...) requires the use of digital terrain models and topographic maps, in this project, we used a digital terrain model-GDEM-ASTER with a spatial resolution of $30 \mathrm{~m}$.

- $\quad$ The land use

The land use map has been extracted from Global Cover Map, which is an ESA initiative that began in 2005 in partnership with JRC, EEA, FAO, UNEP, IGBP and GOFC-GOLD.

The project's objective was to develop a service that can provide composites, global and use maps from input case $300 \mathrm{~m}$ MERIS aboard the ENVISAT satellite emission. ESA provides maps of land cover, which cover two periods: December 2004-June 2006 and from January to December 2009, it is the version used in this project.

- $\quad$ Soil type

The soil map was obtained primarily from the Harmonized World Soil Database's database (HWSD v1.1) developed by Food and Agriculture Organization of the United Nations (FAO-UN) [8]. This database provides data for 16,000 map units containing two different soil layers (0 - $30 \mathrm{~cm}$ and $30-100 \mathrm{~cm}$ deep).

- Hydro-climatic data

All data used in this project are developed by DRWP (The Directorate of Research and the Water Planning), with a daily time step from September 2000 to August 2011.

The Sebou watershed contains 49 stations for measuring rainfall, and the study area (pilot basin Bab-Merzouka) has two stations with one station for measuring temperatures. Three stations for flow measurements are located in the study area (Bani-Haitem, Bab-Ch'houb, and Bab-Merzouka). In our project, the calibration is at the Bab-Mezouka station, the map A (Figure 1) can give an idea about the positioning of the different measurement stations.

The following Table 1 summarizes the information about weather stations in the Sebou river basin and the study area.

- $\quad$ Other climatic parameters

The daily solar irradiance, the daily average relative humidity and the daily average wind speed are downloaded from NCARCFSR (Climate Forecast System Reanalysis), these parameters will help us achieve a WGN (Weather Generator Data) meteorological data generation system.

\section{Data Preparation}

- The maps of the project are completed and processed using a SIG (Arcgis), all layers have the same coordinates and projection systems.

- The input arrays are created for SWAT using the Open Office program (precipitation data, temperature, binding table for soil and use map).

- The statistical variables of meteorological data generation system (weather generator data) are calculated using Excel, pcpstat and dew 02.

\subsection{The Modeling of the Water Balance}

The modeling of the water balance in any hydrological model entitles following a detailed procedure to have results at the end of work, the steps followed while using the SWAT model are summarized in Figure 2.

The coupling of the SWAT model with other SIG (Arcgis) facilitates the work of the modeler, as it allows using the arcgis interface to process and handle all the necessary maps and data.

- $\quad$ The first stage of the modeling on SWAT is based on MNT and the outlet point for the delineation of the watershed and its subbasins.

- The second step is the integration of land use and soil type with the correlation tables between the different types of soil and its occupation and the SWAT database to define our entire HRU watershed.

- The climate data used in this project are the rainfall and temperature with min and max daily time.

- The flows are simulated with a monthly time, because the series of integrated data is very wide, it is extended over a period of 10 years. 


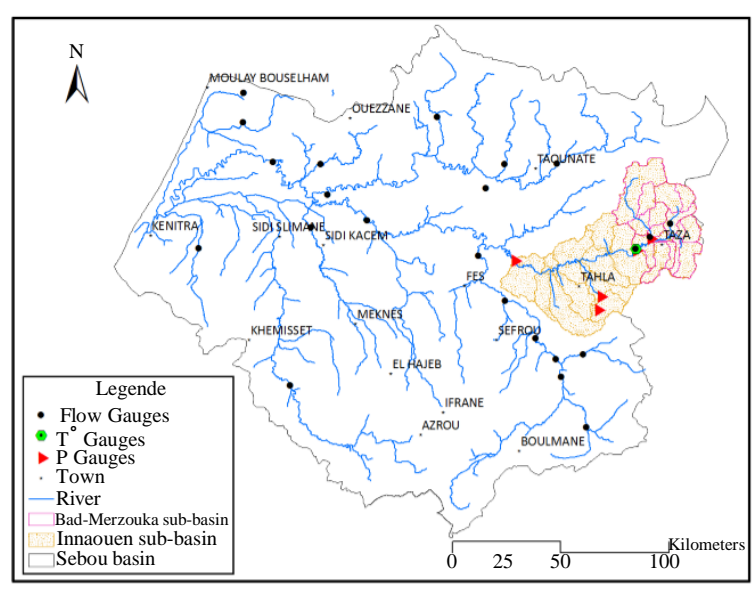

(a)

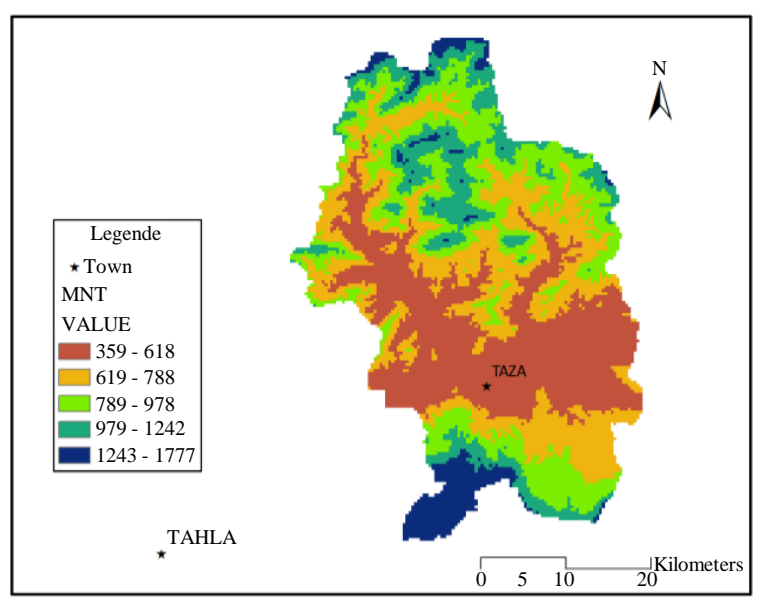

(c)

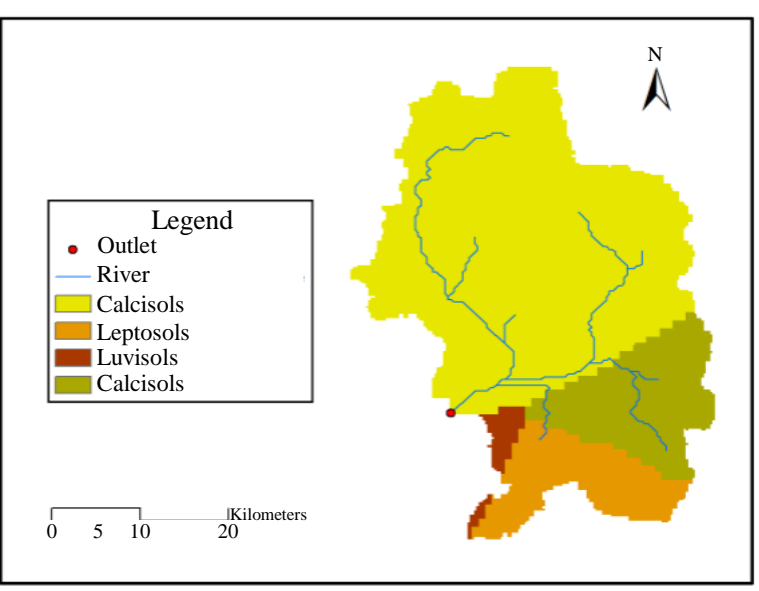

(b)

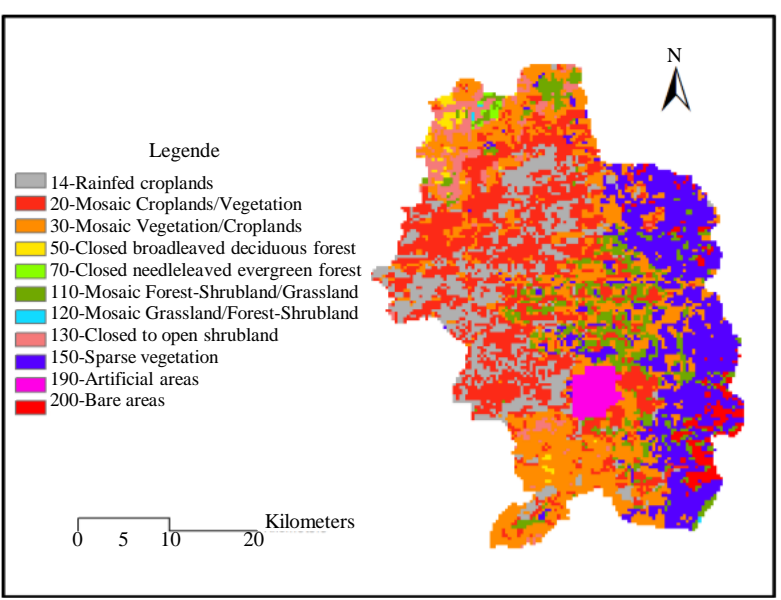

(d)

Figure 1. Basic spatial and weather data input. (a) Location of weather stations; (b) Soil map; (c) Digital Elevation Model (DEM); (d) Land use map.

Table 1. Weather stations in the Sebou river basin and the study area.

\begin{tabular}{cccc}
\hline & $\begin{array}{c}\text { Measuring stations of the } \mathbf{T}^{\circ} \\
\text { (Min/Max) }\end{array}$ & Measuring stations of the $\mathbf{P}(\mathbf{m m})$ & Measuring stations of the flow $\left(\mathbf{m}^{\mathbf{3}}\right)$ \\
\hline Sebou River Basin & - & 49 & 60 (23 with data) \\
Study Area & 1 & 2 & 3 \\
Type of Data & daily & daily & daily \\
\hline
\end{tabular}

- The results reading and the evaluation coefficient calculation are done on a simple data analysis program, Excel.

- $\quad$ Sensitivity analysis can reduce the number of parameters tested for effective use of the model [9].

The sensitivity analysis and the calibrations of the model are made using the SWAT-CUP program.

\subsection{Calibration/Validation Method}

The calibration-validation procedure requires the selection of a period of calibration and a one or more validation periods.

- $\quad$ The calibration period lasts five years, from 2004 to 2008. The calibration involves the adjustment of the model parameters to minimize the differences between observed and simulated flow rates. To do this, we 


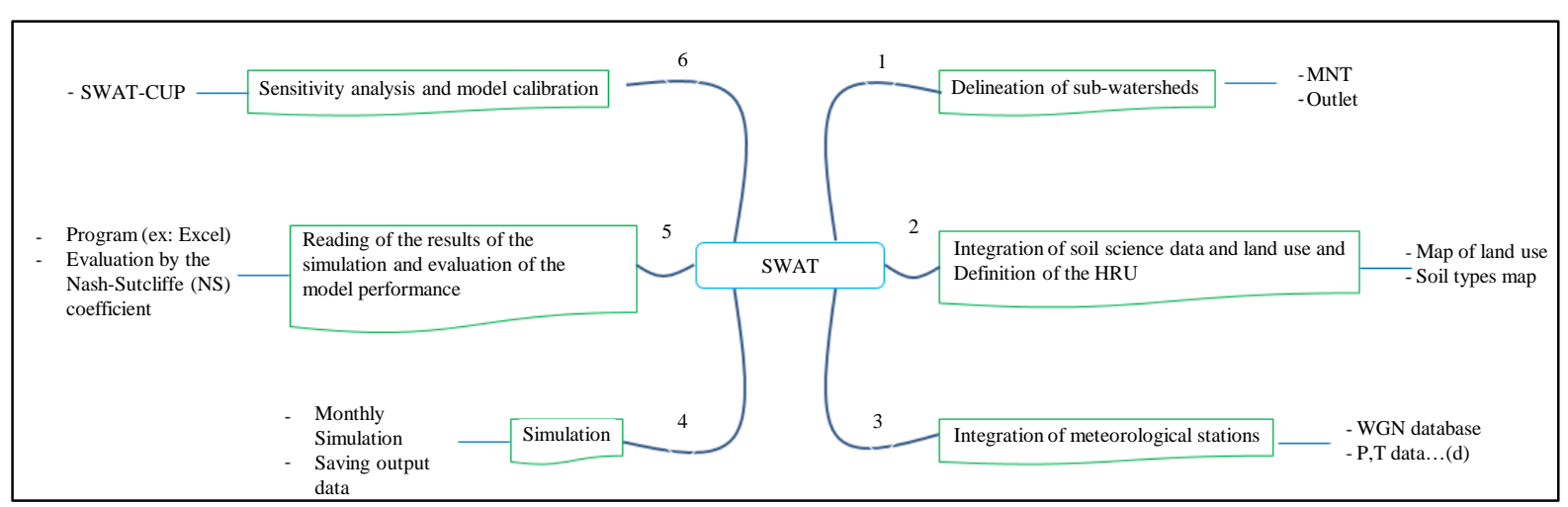

Figure 2. Schematic implementation of SWAT.

vary the most dominant parameters in order to obtain accurate simulation at both the hydrological level from and the physical point of view.

- $\quad$ The validation period allows to assess whether the model has been properly seated, using one or more periods where climatic conditions are different from those of the calibration period. In fact, a robust hydrological model is able to present flow processes whatever the weather involved. In our study, validation is mono-criterion: the same type of variables and criteria is used for calibration and validation. The results of the calibration are validated over a single variable [10], here the flow because it is the most frequently measured variable and the one integrating all the processes involved in a catchment area [11].

- $\quad$ The chosen validation period lasts 2 years, from 2008 to 2010.

- The first year (2003) was used as a warm-up to minimize the effects of the unknown initial conditions, but especially to initialize stocks (soil reserves, groundwater, etc.) and was excluded from the analysis. The calibration there forest arts from 2004 (Figure 3).

\subsection{Evaluation of the Model's Performance}

The adequacy of the curves of the observed discharges and simulated discharges was assessed by the criterion of Nash -Sutcliffe. It is calculated using the formula [12]:

$$
\mathrm{NS}=1-\frac{\sum_{t=1}^{n}(\text { Qot }- \text { Qst })^{2}}{\sum_{t=1}^{n}(\text { Qot }- \text { Qomoy })^{2}}
$$

With:

NS = Nash-Sutcliffe coefficient

Qot $=$ observed discharge at time $t$

Qst = simulated discharge at time $t$

Qomoy = average observed discharges

According Moriasi [13], we can evaluate the performance of the model based on statistical criteria such as NSE; Table 2 gives an overview of what can be achieved when evaluating the model.

\section{Results and Discussion}

To reduce the number of iterations and the calibration time, a sensitivity analysis was done on all the parameters of the SWAT model, of 31 considered parameters, 7 proved influential.

The first seven influential parameters are related to surface runoff (CN2), Floor (SOL-AWC) and the soil evaporation compensation factor ESCO. These settings affect mainly the fraction of the flow contributing to surface runoff, demonstrating that even after the pre-calibration surface runoff adjustment; it can still fluctuate significantly during stalling. Most parameters concerning groundwater flow (ALPHA_BF, GW_DELAY, GWREVAP) come thereafter, further confirming the importance of calibrating the surface runoff.

The physical parameters of the channels (slope, hydraulic conductivity and Manning coefficient) are not to be 


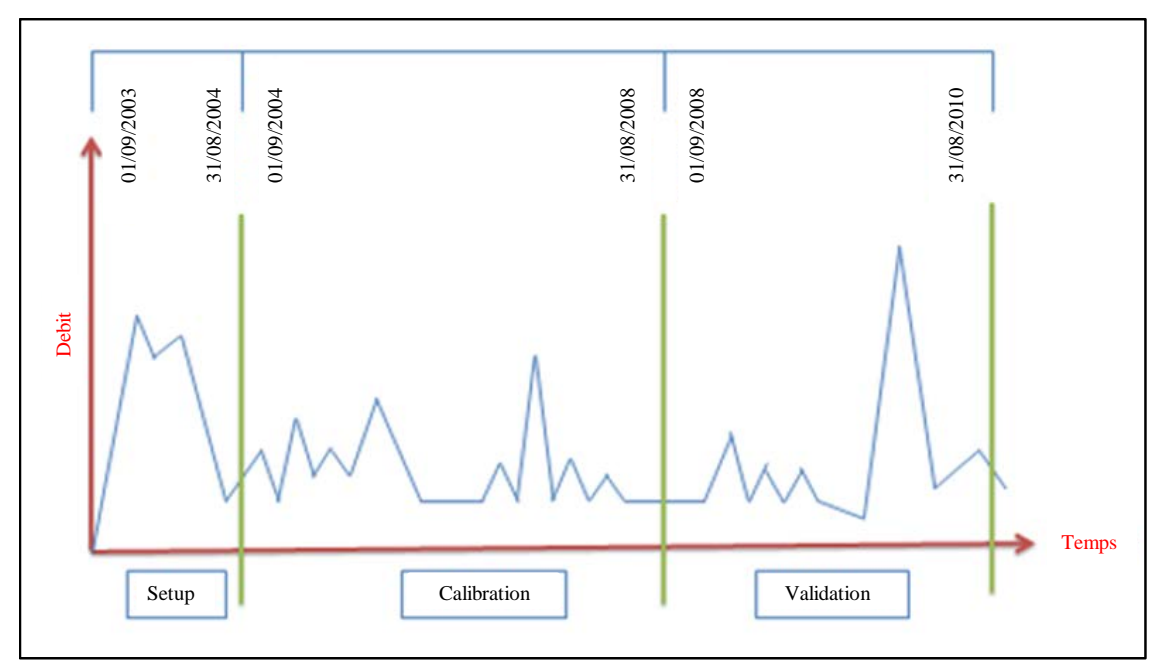

Figure 3. Period of setup, calibration and validation.

Table 2. Performance assessment criteria SWAT [13].

\begin{tabular}{cc}
\hline Performance Evaluation & NS \\
\hline Very good & $0.75<\mathrm{NS} \leq 1.00$ \\
Good & $0.65<\mathrm{NS} \leq 0.75$ \\
Satisfactory & $0.50<\mathrm{NS} \leq 0.65$ \\
Unsatisfactory & $\mathrm{NS} \leq 0.50$ \\
\hline
\end{tabular}

over looked as they also control surface runoff. The chosen setting is (CH-k2) permeability of the banks of the main channels.

Table 3 shows the parameters we have chosen with their meanings and values after calibration and the mathematical method used.

Figures 4 and Figures 5, illustrating the comparison of simulated discharges by SWAT, with observed discharges in tow periods (calibration and validation), show that this model comes to represent in a global way the discharges in the periods studied, taking into account different approximations considered as part of this work for lack of availability of more accurate and spatial data as soil science, rain, temperature and evapotranspiration.

For the evaluation of the performance of models, Nash-Sutcliffe coefficient [11] is used as a criterion to quantify the accuracy of the simulations (Table 4).

Given the results of the modeling, we can draw a conclusion for this study, namely that the SWAT model reproduces satisfactorily the discharges measured on Bab-Merzouka for 2004-2008, as well as the measured discharges for 2008-2010, statistical coefficients (Nash-Sutcliffe) bear witness to a good fit models for the calibration and validation period on the Bab-Merzouka (0.63 in calibration, and 0.74 in the validation).

We must take into account all the difficulties regarding the creation of the database, because obtaining a good simulation performance is primarily conditioned by good quality data, allowing reducing the sources of uncertainty.

The reduction of model performance in the calibration part can be explained by the dry climate that the region knew in the years 2005-2007, which implies very low discharges that are therefore more susceptible to calculate the coefficient of Nash-Sutcliffe [3].

\section{Conclusions}

Within the framework of this study, it concerns testing the hydrological model (SWAT) on a pilot area (BabMezrouka Basin) Sebou Basin to decide the possibility of generalizing on the whole basin. 
Table 3. The parameters used for calibration with optimum values.

\begin{tabular}{cccc}
\hline Parameters & Description & Interval of Variation & Optimal Value \\
\hline CN2 & The curve number & -25 à 25 & -16.5 \\
ALPHA-BF & Coefficient of depletion of groundwater & 0 à 1 & 0.84 \\
GW-DELAY & Groundwater Delay & 30 à 450 & 287 \\
GW-REVAP & Groundwater “revap” coefficient & 0 à 0.2 & 0.2 \\
SOL-AWC & Amount of water available to plants & -25 à 25 & 22.8 \\
ESCO & Compensation factor soil evaporation according to the depth & 0.8 à 1 & 0.86 \\
CH-K2 & Effective hydraulic conductivity of main channel & 5 à 130 & 125 \\
\hline
\end{tabular}

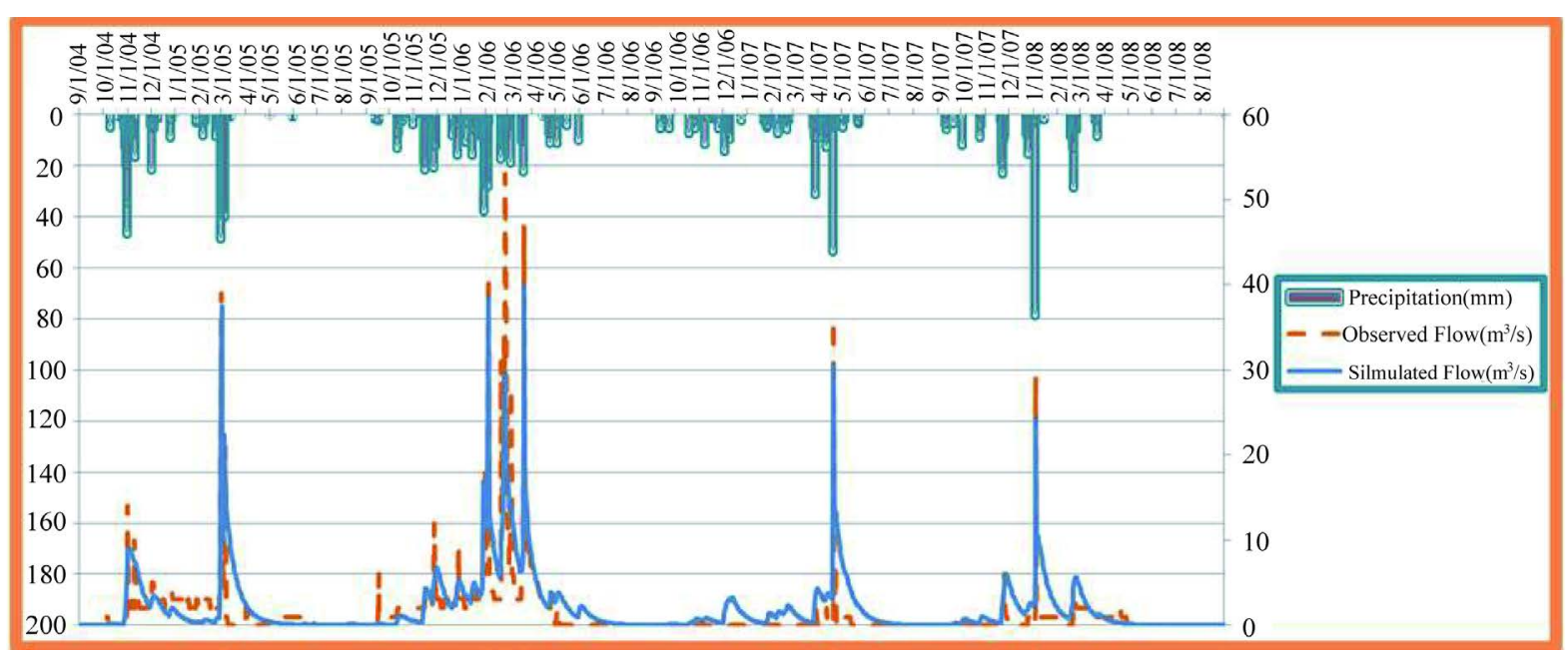

Figure 4. Flow diagram comparing observed and simulated flow for the calibration (2004-2008).

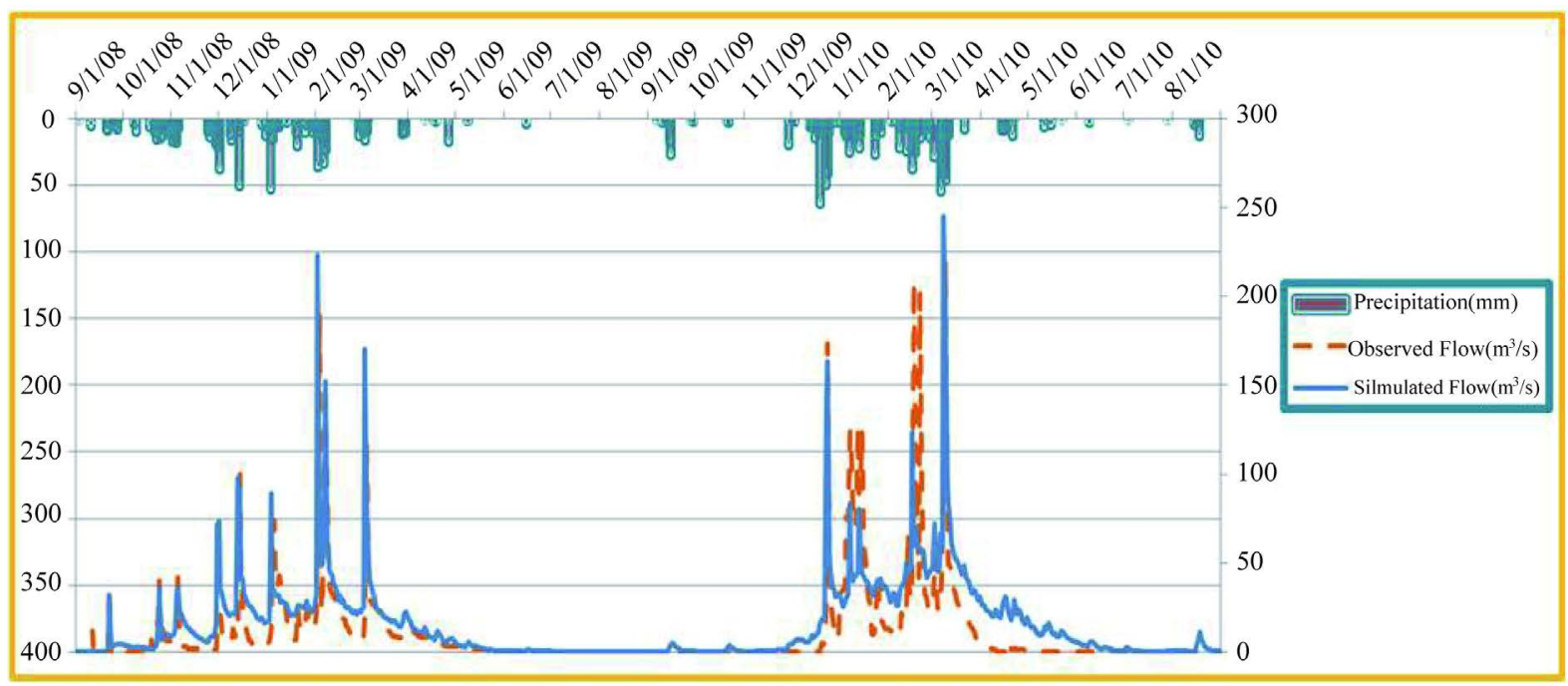

Figure 5. Flow diagram comparing observed and simulated flow for the validation (2008-2010).

Table 4. Nash coefficient result for the period of calibration and validation.

\begin{tabular}{ccc}
\multicolumn{1}{c}{ Period } & Nash Coefficient \\
\hline Calibration period (2004-2008) & 0.63 \\
Validation period (2008-2010) & 0.74 \\
\hline
\end{tabular}


The implementation of this hydrological model is tedious work, as it requires the collection of a spatio-temporal database multi-source and multi-disciplines. This observation becomes more worrisome when it comes to the daily-continued modeling that requires series of data over several years and that affects an area of thousands of square kilometers.

It is therefore a matter of preparing and processing a set of data in the appropriate tools and which are coupled to GIS ArcGIS to deduce there sulting graph of the model and to compare it to the observation graph.

The results obtained for the two periods (calibration and validation) show that this model represents successfully and generally, the discharges on the studied periods taking into account the different problems.

Nevertheless, the simulation can be improved by incorporating additional data, weather, soil... etc.

The use of this model also opens new perspectives on the study of the effects of climate change, and the change induced by human activities on water resources, in both quantity and quality terms.

\section{References}

[1] Meziani, M. and Fornage, N. (2006) Programme de dépollution de l’Oued Sebou. France-Expo, Casablanca.

[2] Rasolomanana, S.D. (2012) Modélisation des petits bassins versants en milieu rural: Problématique des modèles fortement paramétrés. Université Laval, Ville de Québec.

[3] Fadil, A., Rhinane, H., Kaoukaya, A., Kharchaf, Y. and Bachir, O.A. (2011) Hydrologic Modeling of the Bouregreg Watershed (Morocco) Using GIS and SWAT Model. Journal of Geographical Systems, 3, 279-289. http://dx.doi.org/10.4236/jgis.2011.34024

[4] Konyha, K.D., Shaw, D.T. and Weiler, K.W. (1995) Hydrologic Design of a Wetland: Advantages of Continuous Modeling. Ecological Engineering, 4, 99-116.

[5] Kharchaf, Y., Rhinane, H., Kaoukaya, A. and Fadil, A. (2013) The Contribution of the Geospatial Information to the Hydrological Modelling of a Watershed with Reservoirs: Case of Low OumErRbiaa Basin (Morocco). Journal of Geographic Information System, 5, 258-268.

[6] Chaponnière, A., Boulet, G., Chehbouni, A. and Aresmouk, M. (2008) Understanding Hydrological Processes with Scarce Data in a Mountain Environment. Hydrological Processes, 22, 1908-1921. http://dx.doi.org/10.1002/hyp.6775

[7] Arnold, J.G., Moriasi, D.N., Gassman, P.W., Abbaspour, K.C., White, M.J., Srinivasan, R., Santhi, C., Harmel, R.D., Van Griensven, A., Van Liew, M.W., et al. (2012) "SWAT: Model Use, Calibration, and Validation. Transactions of the ASABE, 55, 1491-1508. http://dx.doi.org/10.13031/2013.42256

[8] Nachtergaele, F., Van Velthuizen, H., Verelst, L., Batjes, N., Dijkshoorn, K., Van Engelen, V., Fischer, G., Jones, A., Montanarella, L., Petri, M., et al. (2008) Harmonized World Soil Database. Food Agric. Organ. U. N.

[9] van Griensven, A., Meixner, T., Grunwald, S., Bishop, T., Diluzio, M. and Srinivasan, R. (2006) A Global Sensitivity Analysis Tool for the Parameters of Multi-Variable Catchment Models. Journal of Hydrology, 324, 10-23. http://dx.doi.org/10.1016/j.jhydrol.2005.09.008

[10] Refsgaard, J.C. and Knudsen, J. (1996) Operational Validation and Intercomparison of Different Types of Hydrological Models. Water Resources Research, 32, 2189-2202. http://dx.doi.org/10.1029/96WR00896

[11] Silberstein, R.P., Sivapalan, M. and Wyllie, A. (1999) On the Validation of a Coupled Water and Energy Balance Model at Small Catchment Scales. Journal of Hydrology, 220, 149-168. http://dx.doi.org/10.1016/S0022-1694(99)00075-X

[12] Nash, J.E. and Sutcliffe, J.V. (1970) River Flow Forecasting through Conceptual Models Part I-A Discussion of Principles. Journal of Hydrology, 10, 282-290. http://dx.doi.org/10.1016/0022-1694(70)90255-6

[13] Moriasi, D.N., Arnold, J.G., Van Liew, M.W., Bingner, R.L., Harmel, R.D. and Veith, T.L. (2007) Model Evaluation Guidelines for Systematic Quantification of Accuracy in Watershed Simulations. Transactions of the ASABE, 50, 885900. http://dx.doi.org/10.13031/2013.23153 